\title{
Making the next seven great achievements in pediatric research a reality
}

\author{
Paul J. Chung,MD MS ${ }^{1,2,3,4}$; and the Pediatric Policy Council
}

$I_{h}^{\mathrm{n}}$

$\mathrm{n}$ the September 2016 issue of Pediatric Research, Cheng et al. highlighted seven great achievements in pediatric research in the past $40 \mathrm{y}$. The article was a culmination of a consensusbuilding effort led by the American Academy of Pediatrics, American Pediatric Society, and Society for Pediatric Research, and involving numerous organizations including the Pediatric Policy Council.

The achievements-(i) preventing disease with life-saving immunizations; (ii) reducing sudden infant death with backto-sleep; (iii) curing a common childhood cancer; (iv) saving premature babies by helping them breathe; (v) preventing HIV transmission from mother to baby; (vi) increasing life expectancy for children with chronic disease; and (vii) saving lives with car seats and seat belts-range from basic to population health science and address a wide variety of threats. Cheng et al. emphasize that these achievements were made possible only through a policy-research-policy sandwich-a fundamental political commitment to scientific research followed by the translation of that research into additional policies that benefited millions of children.

Cheng et al. also emphasize that this political commitment may be starting to erode.

\section{IT'S NOT A SANDWICH WITHOUT THE BREAD}

The existence of the policy-research-policy sandwich reveals an uncomfortable truth about research.

The dependence of research on policy is nearly absolute. That might not seem entirely accurate at first glance. A 2010 study in the Journal of the American Medical Association (JAMA), for instance, found that state and federal funding account for less than $40 \%$ of all biomedical research in the United States, while industry pays for nearly $60 \%$ (with the small remainder from private foundations). This examination of research funding streams, however, hides the fact that universities and other research institutions have built enormous infrastructures to support research using nonresearch government dollars (as well as philanthropic donations) that were not counted in the JAMA study. Moreover, even industry-sponsored research is subsidized by state and federal tax relief designed to spur innovation and new products, and relies on regulatory policies and infrastructures that manage the path from design to product to market. Therefore, it is not unreasonable to say that policy determines how much money enters the system, and where that money flows.

The relationship, however, is not bidirectional. The dependence of policy on research is relatively minimal. Without research, policy would still exist_-it might be bad policy, or at least less-informed policy, but it would still be policy. In the policy-research-policy sandwich, research is the replaceable item. The country could easily choose to eat, for instance, a policy-demagoguery-policy sandwich, or a policy-emotional anecdote-policy sandwich, or a policy-good old common sense-policy sandwich, and we have all seen numerous instances where, in fact, it has. On the other hand, if researchers were to abandon, or at least ignore, policy, we would simply end up without a sandwich.

\section{HOW DO WE REMIND POLICYMAKERS THAT RESEARCH MAKES SANDWICHES GREAT?}

If we ignore policy, erosion of political commitment to biomedical research will become an unstoppable train. But we are not there yet. In fact, Congress recently granted the first substantial increase to the National Institutes of Health (NIH) budget in years.

The warning signs are clear, however, and long-term erosion may end up resulting from various factors. First, there is a growing unease regarding scientific bias in general, in part because mainstream science has become increasingly identified by the public as partisan (e.g., evolution, climate change) and corrupt (e.g., industry-sponsored research). Second, there is growing general unease regarding scientific accuracy, in part because health recommendations are perceived to be made and then reversed years later on a seemingly routine basis, and issues like the "replication crisis" in research have gained attention. Third, there is a growing public perception that the "healthcare-industrial complex" has for many years been successful at enriching itself at the expense of other sectors. Of the 12 highest-paid professions tracked by the US Bureau of Labor Statistics, doctors and dentists occupy 11 of them. Fair or not, true or not, biomedical research is considered a part of that same complex. Finally, there is growing public uncertainty about the degree to which biomedical research actually helps

\footnotetext{
'Department of Pediatrics, UCLA, Los Angeles, California; ${ }^{2}$ Department of Health Policy and Management, UCLA, Los Angeles, California; ${ }^{3}$ RAND Health, RAND Corporation, Santa Monica, California.; ${ }^{4}$ Children's Discovery \& Innovation Institute, Mattel Children's Hospital UCLA, Los Angeles, California.Correspondence: Paul J. Chung (PaulChung@mednet.ucla.edu) 


\section{Makingthenextsevengreatachievementsinpediatricresearchareality|PolicyCommentary}

people, and the country as a whole, achieve our most pressing goals. When parents are being told that their children may grow up to be less well-off than they, and to die sooner than they, despite years of investment in biomedical research, they may begin to ask whether pediatric research is really a good use of our resources.

The genius of the seven great achievements is that they addressed the real concerns of vast numbers of parents. Each of these achievements leads directly to the following argument: "Because of this, every parent (or parent-in-waiting) wakes up every morning feeling more secure." That is the kind of argument that restores faith and political commitment in biomedi$\mathrm{cal}$ research. And that is the kind of goal that every researcher needs to envision their work will ultimately create, and the kind of vision that the research community needs to articulate and promise.

We can advocate all we want about the need to increase pediatric research funding, about the fact that children account for a quarter of the population and $100 \%$ of its future but receive only $15 \%$ of research dollars, about the need to maintain and strengthen the pipeline for pediatric research trainees, about the need to create sustainable pay-lines for pediatric research at NIH and all federal agencies, and about the financial burdens placed on academic institutions whose missions include both supporting pediatric research and serving large numbers of underserved children. And we do!

We can argue proactively for changes that will highlight pediatric research-like elevating inclusion of children in NIH reporting to the same level as inclusion of women and minorities, arguing that children should be front-and-center in major scientific endeavors such as the Precision Medicine Initiative, and advocating for pediatric-specific research initiatives like the Gabriella Miller Kids First Pediatric Research Program and the Environmental Influences on Child Health Outcomes program. And we do!

But ultimately, the most important thing we can do is to demonstrate, through our work, how pediatric research makes children and families stronger, and to advocate passionately for all innovations, activities, and programs that research informs us will make children and families stronger. Only if we inspire belief in what's possible will the long-term policy conditions necessary for the next seven great achievements in pediatric research (whatever those achievements may be) become a reality. 